\title{
Biosurfactants in industry
}

\author{
N. KOSARIC \\ Department of Chemical and Biochemical Engineering \\ University of Western Ontario, London, Ontario, Canada, N6A 5B9
}

\begin{abstract}
Biosurfactants (Microbial Surface Active Agents) have become recently an important product of biotechnology for industrial and medical applications. Thereason for their popularity, as high value microbial products, is primarily in their specific action, low toxicity, relative ease of preparation and widespread applicaility. They can be used as emulsifiers, de-emulsifiers, wetting agents, spreading agents, foaming agents, functional food ingredients and detergents in various industrial sectors such as Petroleum and Petrochemicals, Organic Chemicals, Foods and Beverages, Cosmetics and Pharmaceuticals, Mining and Metallurgy, Agrochemicals and Fertilizers, Environmental Control and Management, and many others.
\end{abstract}

\section{INTRODUCTION}

The unique properties of biosurfactants allow their use and possible replacement of chemically synthesized surfactants in a great number of industrial operations. Surfactants are used by many industries and one could easily say that there is almost no modern industrial operation where properties of surfaces and surface active agents are not exploited. The potential application of biosurfactants in industries is also a reality.

There are many advantages of biosurfactants as compared to their chemically synthesized counterparts. Some of those are:

a) Biodegradability.

b) Generally low toxicity.

c) Biocompatability and digestibility, which allows their application in cosmetics, pharmaceuticals and as functional food additives.

d) Availability of raw materials. Biosurfactants can be produced from cheap raw materials which are available in large quantities. The carbon source may come from hydrocarbons, carbohydrates and/or lipids, which may be used separately or in combination with each other.

e) Acceptable production economics. Depending, on the application, biosurfactants can also be produced from industrial wastes and byproducts and this is of particular interest for bulk production (e.g. for use in petroleum related technologies).

f) Use in environmental control. Biosurfactants can be efficiently used in handling industrial emulsions, control of oil spills, biodegradation and detoxification of industrial effluents and in bioremediation of contaminated soil.

g) Specificity. Biosurfactants, being complex organic molecules with specific functional groups, are often specific in their action. This would be of particular interest in detoxification of specific pollutants, de-emulsification of industrial emulsions, specific cosmetic, pharmaceutical and food applications.

Concerning disadvantages, one of the problems is related to large scale and cheap production of biosurfactants. Large quantities are particularly needed in petroleum and environmental applications, which, due to the bulk use, may be expensive. To overcome this problem, processes should be coupled to utilization of waste substrates combating at the same time their polluting effect, which balances the overall costs. 
Another problem may be encountered in obtaining pure substances which is of particular importance in pharmaçeutical, food and cosmetic applications. Downstream processing of diluted broths may be quite involved requiring multiple consecutive steps. Therefore, high yields and biosurfactant concentrations in bioreactors are essential for their facilitated recovery and purification.

Most of the biosurfactants are high molecular weight lipid complexes which are normally produced under highly aerobic conditions. This is achievable in their ex-situ production in aerated bioreactors. When their large scale application in petroleum and soil is encountered, their in-situ production (and action) would be advantageous. Low oxygen availability under these conditions requires maintenance of anaerobic microorganisms and their anaerobic synthesis of biosurfactants, whereby other conditions for microbial growth are also most unfavourable (e.g. mixing, availability of substrate, mass transfer, availability of trace nutrients, etc.). Screening for anaerobic biosurfactant producers is for these conditions of great importance ${ }^{1}$.

In terms of their structure, biosurfactants are

\author{
-Hydroxylated and cross-linked \\ fatty acids \\ -Polysaccharide-lipid complexes. \\ -Glycolipids \\ -Lipoprotein-lipopeptides \\ -Phospholipids \\ -Complete cell surfaces.
}

They are produced by various microorganisms as shown in Table 1 , and being predominantly lipids, their biosynthesis is promoted when nitrogen becomes deficient in the medium.
TABLE 1. Various Biosurfactants Produced from Different Microbes

\begin{tabular}{ll}
\hline Microbe & Type of surfactant \\
\hline Torulopsis bombicola & Glycolipid (sophorose lipid) \\
Pseudomonas aeruginosa & Glycolipid (rhamnose lipid) \\
Bacillus licheniformis & Lipoprotein (surfactin) \\
Bacillus sub tilis & Lipoprotein (sufactin) \\
Pseudomonas sp. DSN 2874 & Glycolipids (rhamnose lipid) \\
Arthrobacter paraffineus & Sucrose and fructose \\
& glycolipids \\
Arthrobacter & Glycolipid \\
Pseudomonas fluorescens & Rhamnose lipid \\
Pseudomonas sp. MUB & Rhamnose lipid \\
Torulopsis petrophilum & Glycolipid and/or protein \\
Candida tropicalis & Polysaccharide-fatty acid \\
& complex
\end{tabular}

\section{BIOSURFACTANTS PRODUCTION BASED ON WASTE}

If industrial and/or municipal wastewaters, which contain organic pollutants could be utilized as substrates for biosurfactant production, a double benefit would be obtained: The polluted waters would be treated and a valuable product would result. This approach reduces the cost for wastewater treatment with even a potential of generating a profit through the sale of the biosurfactant.

Having the above considerations in mind we have developed two strategies for such approach ${ }^{3}$.

Torulopsis bombicola was chosen as a model organism for biosynthesis of sophorose lipids, which are of interest in cosmetics and other industries. This yeast can give a high concentration of $67 \mathrm{~g} / \mathrm{L}$ of sophorose lipid with a yield of $0.347 \mathrm{~g} / \mathrm{g}$ substrate $\mathrm{s}^{4}$. In our most recent experiments (poster at this conference) a yield of $137 \mathrm{~g} / \mathrm{L}$ sophorose lipids was obtained. Both sugar and vegetable oil are required for maximum yields.

Using inexpensive and commercially available substrates (molasses + soybean oil) it was calculated ${ }^{3}$ that the substrates alone would place the biosurfactant production cost at about Can. $\$ 1.00 \mathrm{~kg}$ and total production cost at about Can. $\$ 3.00 / \mathrm{kg}$. The price of commercial surfactants of the non-ionic alcohol ethoxylate and alkylphenoletoxylate types for use in EOR has been estimated to Can. $\$ 1.4-1.6 / \mathrm{kg}$.

This clearly shows that, when molasses as the substrate is used, the biosurfactant becomes more expensive than the chemically synthesized surfactant. However, the sophorose lipids use in cosmetics may be advantageous as compared to the use of the synthetic surfactant, for the same cosmetic application. The mentioned multiorganism strategy was used to reduce these production costs. As 


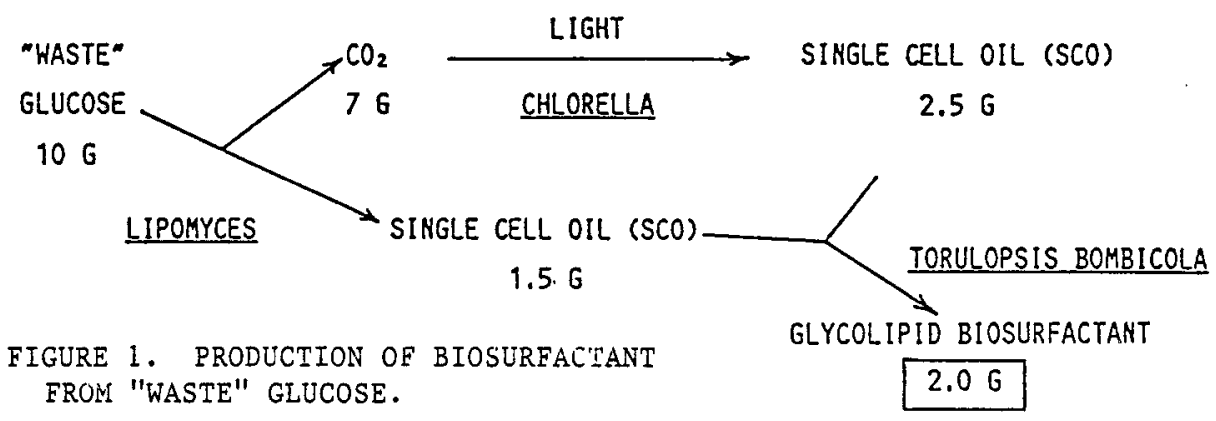

illustrated in Figure 1, the substrate is "waste" glucose which may come from food processing, agriculture or from a variety of industrial operations (e.g. rice hull hydrolysate, starch waste liquors, whey, domestic waste, potato processing waste, waste liquor from instant rice production, waste sulfite liquor, etc.). In this approach an appropriate lipogenic bacterium or yeast (see Table 2 for some possible microorganisms) and the appropriate lipogenic algae (Chlorella or other) are cocultured to produce microbial single cell oil in the form of triglyceride. The microbial triglycerides and the same sugar are used by T. bombicola to produce the glycolipid. An approximate material balance shows that this process would produce a $600 \%$ increase in biosurfactant yield from sugar alone compared with a single organism strategy which produces only $0.032 \mathrm{~g}$ biosurfactant/g sugar.

TABLE 2. Lipid Accumulating Microbes Which Could be Used to Produce Triglyceride Precursors to Biosurfactants

\begin{tabular}{|c|c|c|c|c|}
\hline & & Substrate & $\begin{array}{c}\text { Total lipid } \\
\text { as a } \% \text { biomass } \\
\text { (\% neutral lipid) }\end{array}$ & $\begin{array}{c}\text { Lipid yield } \\
\text { (g lipid/loog } \\
\text { sugar) }\end{array}$ \\
\hline Liponyces lipofer & yeast & glucose & $\begin{array}{r}60-65 \\
(80)\end{array}$ & 22.0 \\
\hline Rhodotorula gracilis & yeast & glucose & $\begin{array}{r}55-65 \\
(75)\end{array}$ & 16.0 \\
\hline Chlorella vulgaris & algae & $\mathrm{CO}_{2}$ & $\begin{array}{c}30 \\
(65)\end{array}$ & - \\
\hline Chlorella pyrenoidosa & algae & $\mathrm{CO}_{2}$ & $\begin{array}{r}65-75 \\
(70)\end{array}$ & - \\
\hline Chlorella sorokinana & algae & $\mathrm{CO}_{2}$ & $\begin{array}{c}45 \\
(80)\end{array}$ & - \\
\hline Arthrobacter AKI9 & bacteria & glucose & $\begin{array}{l}80 \\
(90)\end{array}$ & 14.0 \\
\hline
\end{tabular}

By another strategy, municipal waste sludge could be used as substrate in an anaerobic treatment process, followed by partial hydrolysis of anaerobic sludge on which lipogenic microbes could be grown. Several advantages of this approach are:

a) Only one feedstock is used. Biosurfactant can be produced at the waste treatment site.

b) The feedstock (activated sludge from conventional wastewater treatment) is already centrally collected and anaerobic digester may already be in place.

c) There is a cost credit for environmental benefit.

d) The feedstock is available year-around.

e) Energy requirements can be met by the production of methane (anaerobic digestion).

f) Process if relatively simple.

Torulopsis biomass from biosurfactant production can be recycled to the front end of the entire process for treatment, or it can be separated from the medium and sold as yeast-rich feed supplement. Thus, five final products are obtained:

-biosurfactant (sophorose lipids)

-biogas (70-80\% methane) -treated water

-high grade biomass (yeast) -low grade biomass

(anaerobic sludge) 


\section{BIOSURFACTANTS IN PETROLEUM PROCESSING INDUSTRIES}

Most of the interest in use of biosurfactants in petroleum related industries is for Enhanced Oil Recovery (EOR). For this utilization, biosurfactants can be used extra situm ${ }^{5}$ and in situ ${ }^{6}$. In both cases, biosurfactants are applied (as a replacement or addition to synthetic surfactants) to enhance oil recovery from the ground, which by primary pumping methods is possible only to about $30 \%$ recovery from the reservoir. The presence of surfactant (or biosurfactant!) lowers the surface and interfacial tensions of the oil in the reservoir, which facilitates oil flow and penetration through pores in the reservoir during water, steam or fire flooding recovery operations, as practices in EOR (or Microbial EOR, MEOR).

For production of the biosurfactant (extra situm), the selected culture is grown in bioreactors, the biosurfactant recovered or simply concentrated in the broth and then pumped into the reservoir. This external production of the biosurfactant must be in large quantity, under optimum fermentation conditions, supplying sufficient aeration to the culture in the bioreactor. Use of cheap and waste substrates for this application would be particularly advantageous.

A logical and more attractive approach is to produce the biosurfactant in the reservoir itself (in situ) by providing nutrients to indigenous microbial population in the reservoir or to a seed culture which is produced extra situm, mixed with the medium and pumped into the well.

However, microorganisms introduced in this way into the reservoir are subjected to a number of stresses which may affect their growth or even inhibit both growth and biosurfactant production. Temperatures in the reservoir may be too high and the effect of pressure on microbes placed there is also not well understood. Macrobial growth and biosurfactant production are also affected by $\mathrm{pH}$, salinity, heavy metals which also may considerably differ from those for optimum biosurfactant production.

One of the major difficulties in maintaining microbial growth and thus biosurfactant production in the reservoir is the lack of oxygen and proper mixing in the reservoir to ensure good mass transfer and nutrient metabolism by the organisms.

Also,biosurfactants produced in situ must exert their action at the targeted sites, which cannot be easily controlled. Some crude oil in the reservoir could also be metabolized. However, oxygen is needed for metabolism of hydrocarbons and aeration downhole is anathema to oil producers who go to great lengths to deoxygenate injection fluids. Oxygen would also cause corrosion of metal work and degrade the product in situ turning a light high-value oil into heavy lower grade oil which would be even more difficult to extract by water flooding.

A problem may also arise if biomass starts blocking some pores in the reservoir. If this could be controlled some preferential plugging and thus directing the flood would even be beneficial. A further drawback when MEOR is practised, is that the water flood can no longer be treated with chlorine or organic biosides. Thus at long MEOR, the continuing water flood would carry non-biosurfactant producing bacteria into the reservoir, which if conditions prevail could result in secondary population which would compete with the substrate for biosurfactant producers.

Besides, all the above difficulties of in situ MEOR, the amount of oil left in the reservoir after secondary recovery methods have been tried, represents an enormous amount of oil (60-70\% of original) for extraction, and further efforts in MEOR are challenging.

\section{MICROBIAL DEEMULSIFICATION}

Another biosurfactant property of microbial cells is destabilization of oil-in-water and water-in-oil emulsions. In an attempt to break such industrial emulsions generated in EOR (W/O)and in processing of tar sands $(\mathrm{O} / \mathrm{W})$, specific bacterial cells were utilized ${ }^{7}$. It was shown that bacterial cell surfaces can enhance deemulsification of simple model emulsions (kerosene/water) as well as complex field emulsions obtained in EOR. Some results are presented in Figure 2. The W/O emulsions were easier broken when bacteria (e.g. Nocardia amarae) harvested at early stage of growth (day 1) were used. Oilin-water $(\mathrm{O} / \mathrm{W})$ emulsions, on a contrary, were efficiently broken with "old" cells, i.e. those harvested at later stage of growth. It is also interesting to note that this deemulsification activity was difficult to destroy (by various drastic chemical treatments) and that the activity of these cells was not lost even after autoclaving the cells at $120^{\circ} \mathrm{C}$ for 30 minutes, i.e. dead cells retained their activity which is an important factor for their industrial application. 


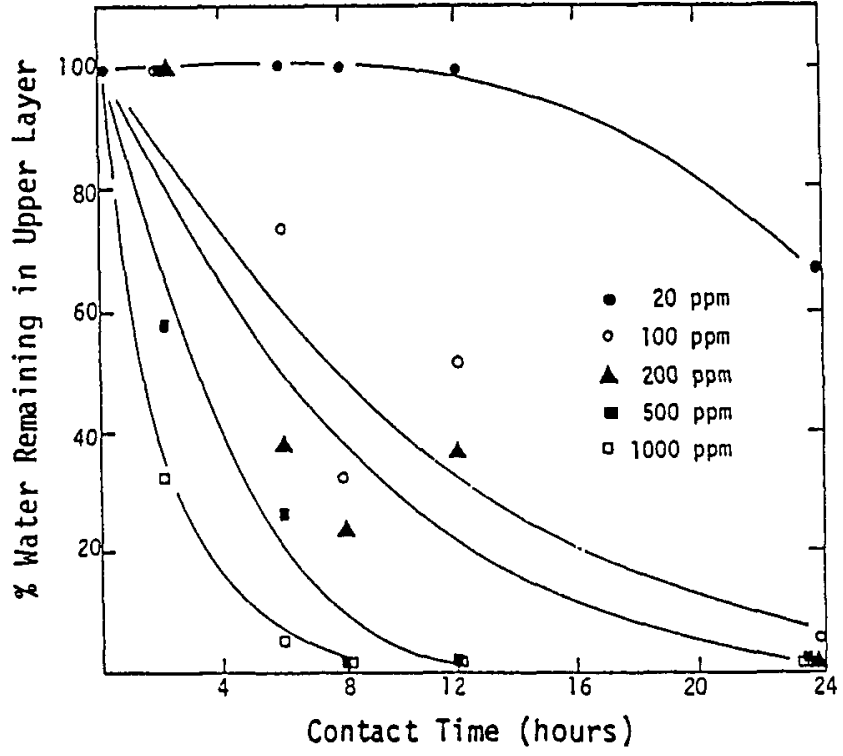

Figure 2.

The de-emulsifying ability of day 1 cells of $N$. amarae acting on emulsion \#2 at various concentrations of bacteria.

Various factors may be involved in the deemulsification process as shown in Table 3. By measuring the cell contact angle to hydrocarbon droplets, the hydrophobicity (increased contact angle) of the cells can be quantified.

There is a large variety of cell wall components which could contribute to cell surface hydrophobicity. In the glycocalyx (slime, capsule)-o-acetylated and pyruvate ketals of polysaccharide or globular glycoproteins are found. The outer membranes of Gram negative bacteria contain lipopolysaccharides, lipoproteins, phospholipids and hydrophobic proteins; while cell wall components of Gram positive bacteria are characterized by lipoteichoic acids and acylated polysaccharides such as mycoloyl arabinogalactans of Mycobacteria, Nocardia and Corynebacteria.

\section{TABLE 3. General Factors Influencing Bacteria-Induced De-emulsification}

(1) Factors influencing bacterial cell surfaces

(a) Species-specific genetic potential for cell wall biochemistry (hydrophobic, hydrophilic, charged, etc., molecules)

(b) Metabolic state of cell influencing expression of genetic potential

(i) Coll cycle (averaged in nonsynchronized culturos)

(ii) Availability of $\mathrm{C}, \mathrm{N}, \mathrm{O}$, etc.

(iii) Substrate form (e.g., sugars vs. alkanes)

(c) Physical organization of cell wall biochemicals at the cell surface

(d) Binding of extracellular surface-active molecules of biological origin to the cell surface

(i) Secreted metabolic byproducts

(ii) Products of cell autolysis

(iii) Lipids extracted from cells by organic substrates

(2) Factors of nonbiological origin influencing interfacial and rheological properties of the system
(a) Orgunic phuse composition
(b) Aqueous phase composition (salts, $\mathrm{pH}$ )
(c) Nature of emulsion-stabilizing surfactants
(d) Presence of fine particulates (e.g., clays)
(e) Temperature 


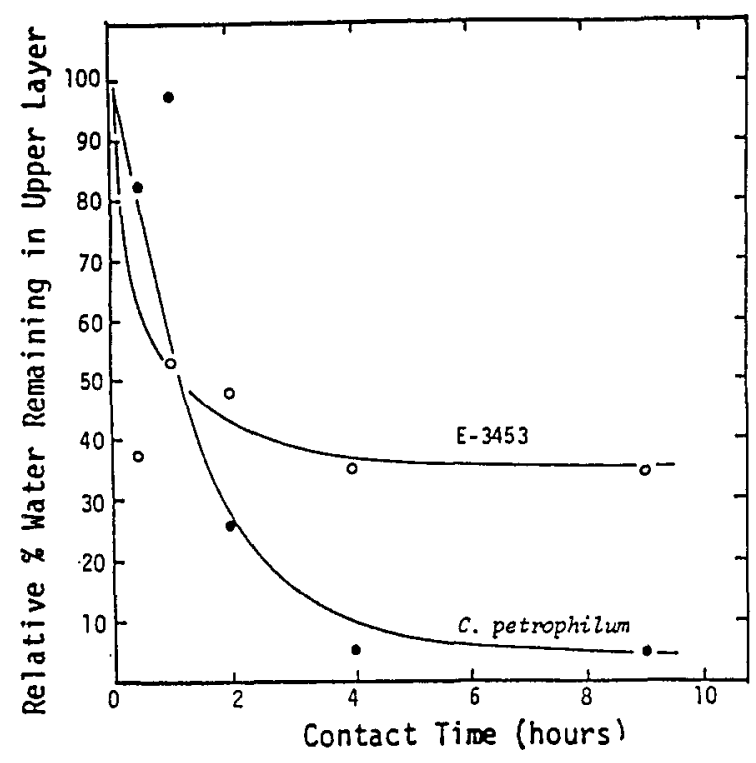

Figure 3. A comparison of the de-emulsification abilities of $C$. petrophilum (day $1 ; 500 \mathrm{ppm}$ ) and the commercial de-emulsifier Tretolite E- 3453 (1000 ppm) acting on the field emulsion 1-JB-15-9.

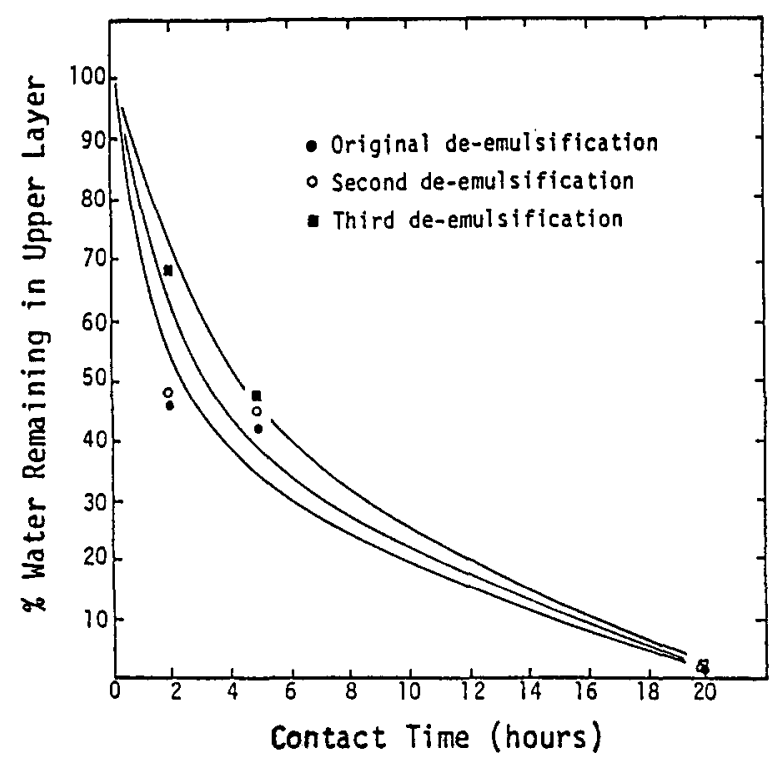

Figure 4. The effect of re-using a bacterial deemulsifier (500 ppm C. petrophilum; day 1 cells) on the 1-JB-15-7 W/O emulsion.

De-emulsification of W/O emulsions requires hydrophylic cell surfaces which exist around cells growing exponentially or in early stationary phase. On the other hand, de-emulsification of $\mathrm{O} / \mathrm{W}$ emulsions require hydrophobic surfaces which could be produced during the endogenous metabolic phase by acilation of the exopolysaccharides and deposition in the outer cell layers of free, non-covalently bound carboxylic acids and/or other biosurfactants which are liberated by excretion or cell lysis. Under $\mathrm{O}_{2}$ limiting conditions, polyhydroxybutyric acid (PHB) and its monomer may play a significant role in increasing cell surface hydrophobicity.

The efficiency of bio-deemulsifiers is comparable and can be better than for the synthetic ones (depending on the emulsion). One such comparison is shown in Figure 3. They also can be recycled and reused without appreciable loss of activity, as shown in Figure 4. Advantages are also seen when bacteria are applied together with synthetic deemulsifiers (Figure 5)

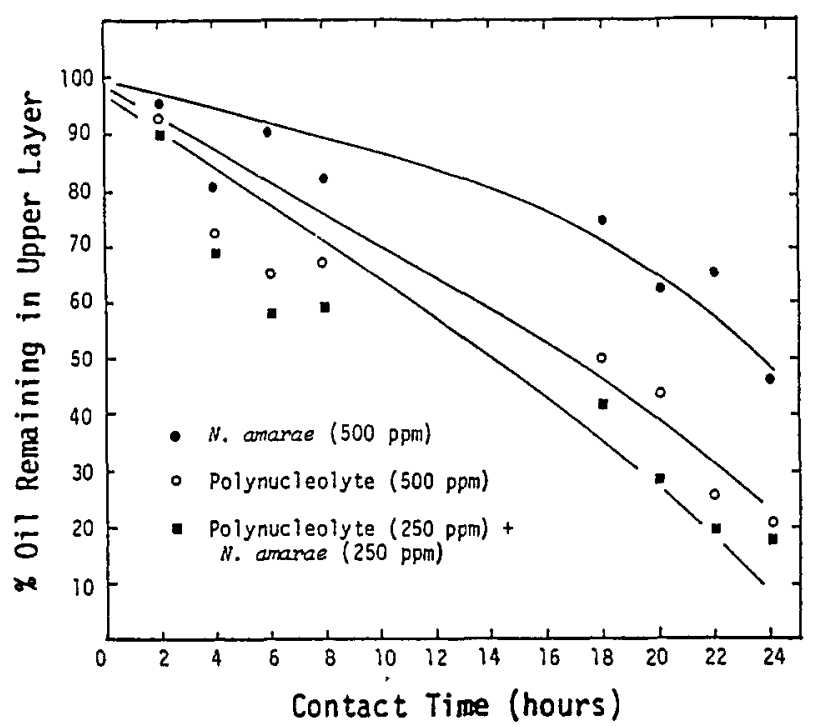

Figure 5. The effect of the flocculating agent Polynucleolyte on the $\mathrm{K} 9 \mathrm{ON}$ emulsion compared to the de-emulsifying abilities of $N$. amarae (day 19)
TABLE 4. Properties of Food Surfactants

\begin{tabular}{|c|c|}
\hline $\begin{array}{l}\text { General surface- } \\
\text { active properties }\end{array}$ & $\begin{array}{l}\text { Emulsifier } \\
\text { Demulsifier } \\
\text { Solubilizer } \\
\text { Suspension agent } \\
\text { Wetting agent } \\
\text { Foaming agent }\end{array}$ \\
\hline & $\begin{array}{l}\text { Defoaming agent } \\
\text { Thickener } \\
\text { Lubricating agent } \\
\text { Protecting agent }\end{array}$ \\
\hline $\begin{array}{l}\text { Food-specific } \\
\text { properties }\end{array}$ & $\begin{array}{l}\text { Interaction with lipids } \\
\text { Interaction with proteins } \\
\text { Interaction with carbo- } \\
\text { hydrates }\end{array}$ \\
\hline
\end{tabular}




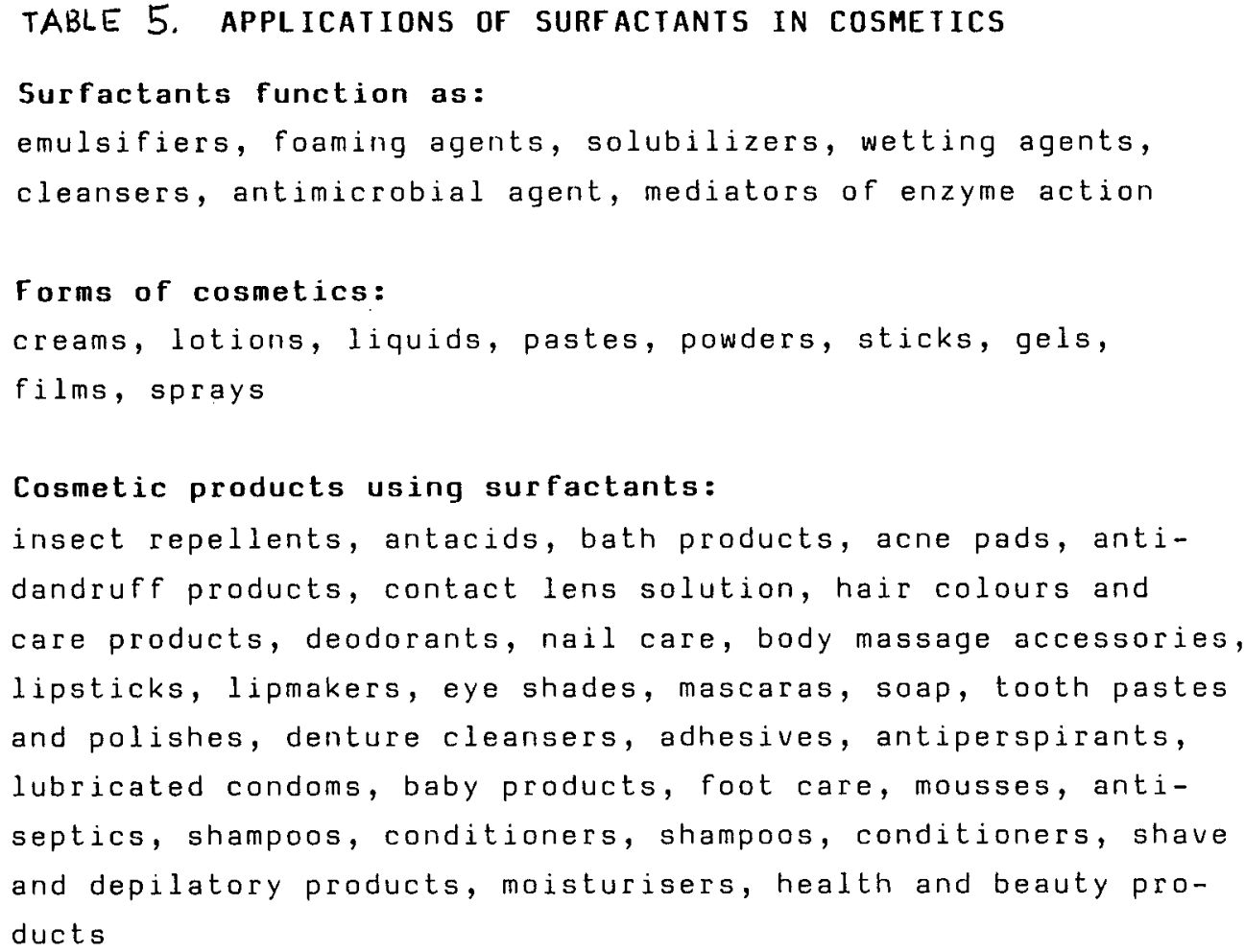

\section{BIOSURFACTANTS FOR COSMETIC AND FOOD APPLICATIONS}

There is restricted data available for use of biosurfactants in cosmetic and food applications.

Many biosurfactant properties such as emulsification and de-emulsification, foaming, water binding capacity, spreading and wetting properties effect on viscosity and on product consistency, can efficiently be utilized by the above industries.

Emulsifiers are important additives to many food as well as cosmetic preparations. Some properties of food surfactants are listed in Table 4. Application of surfactants in cosmetics is shown in Table 5.

\section{REFERENCES}

1. McInerney, M.J., Javaheri, M. and Nagle, D.P. Ind. Microbiology 5,95-102,1990.

2. Boulton, C.A. and Ratledge, C., in Kosaric, N., Gray, N.C.C. and Cairns, W.L. (eds): Biosurfactants and Biotechnology, 48-87, 1987.

3. Kosaric, N., Cairns, W.L., Gray, N.C.C., Stachey, D.M. and Wood, J. Oil Chem.Soc. 61(II), 1735-1743, 1984.

4. Cooper, D.G. and Paddock, D.A. Appl. Env. Microbiology 47, 173-176, 1984.

5. Bubela, B. in: Kosaric,N., et al. (eds) Biosurfactants and Biotechnology, pp. 143-161,Marcel Dekker, New York, 1987/

6. Shennan, J.L. and Levi, J.D. in: Kosaric, N.,et al. (eds) biosurfactants and Biotechnology, pp. 163-181, Marcel Dekker, New York, 1987.

7. Kosaric, N., Cairns, W.L. and Gray,N.C.C. Microbial De-emulsifiers. in: Kosaric,N. et al. (eds) Biosurfactants and Biotechnology, pp. 248-321, Marcel Dekker, New York, 1987. 